\title{
Studi Kualitatif Pola Konsumsi Masyarakat Kota Jambi pada Bulan Ramadhan Berdasarkan Faktor Sosial
}

\author{
Habriyanto \\ Fakultas Ekonomi dan Bisnis Islam \\ Universitas Islam Negeri Jambi Sulthan Thaha Saifuddin Jambi, Indonesia \\ Correspondence Email: habriyanto781@gmail.com
}

\begin{abstract}
This research is related to a qualitative study relating to the consumption patterns of the Jambi city community in the month of Ramadan relating to the qualitative influence of social factors on consumption patterns. The research motive uses quality research with questionnaire data collection tools and analyzed descriptively. The results showed that the Jambi city community had made family, friends and print and electronic media as a reference in consuming during the month of Ramadan. Meanwhile the provision of consumption for Eid is largely determined by the condition of the social class in society. Then the things that shape consumption patterns in the month of Ramadan are culture such as the provision of ta jil, preparation for Eid consumption, going home and giving gifts to relatives.
\end{abstract}

Keyword: comsumption pattern; social factors

\section{PENDAHULUAN}

Kegiatan perekonomian masyarakat mempunyai siklus kegiatan mulai dari kegiatan produksi, distribusi dan konsumsi. Kegiatan produksi dimulai dari kemampuan masyarakat untuk memproduksi sebuah barang yang bernilai ekonomis dan didistribusikan kepada konsumen yang membutuhkan yang juga bagian dari anggota masyarakat. Komponen yang saling berkaitan tersebut akan silih berganti dialami oleh setiap anggota masyarakat dalam aktivitas kehidupannya. Kegiatan konsumsi adalah bagian dari siklus komponen yang sering dibicarakan dalam kegiatan perekonomian. Dimana kegiatan konsumsi mesti akan dilakukan setiap individu sebagai rangkai dari pemenuhan kebutuhan mereka sehari-hari yang setiap orang tentu akan berbeda pola konsumsi dalam memenuhi kebutuhan. Pola konsumsi tentu dipengaruhi oleh berbagai macam faktor yang mempengaruhi sebagai bentuk stimulus seperti keinginan dan pertimbangan kepentingan dalam dalam mengkonsumsi sebuah barang. Interaksi sosial adalah bagian dari salah satu faktor yang mempengaruhi pola konsumsi atau keputusan dalam mengkonsumsi. Faktor sosial tersebut berupa pengaruh kelompok referensi seperti keluarga, teman dan masyarakat sekitar. Pengaruh kelas sosial, status sosial dan kebudayaan pada masyarakat adalah bagian dari pengaruh faktor sosial terhadap pola konsumsi pada sebuah komunitas masyarakat.

\section{Peningkatan Konsumsi Rumah Tangga Pada Bulan Ramadhan di Kota Jambi}

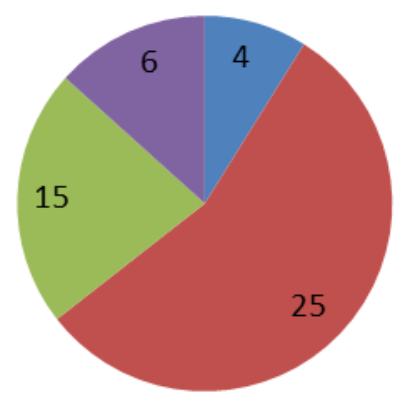

Sumber: data diolah dari wawancara

\section{Gambar 1}

Peningkatan Konsumsi Rumah Tangga Pada Bulan Ramadhan di Kota Jambi 
Bulan Ramadhan adalah bagian dari bulan yang terdapat dalam nama-nama bulan dalam Islam. Pada saat memasuki bulan Ramadhan umat Islam akan menjalan kegiatan ibadah yaitu berpuasa di siang hari di mulai dari terbit fajar hingga terbenam matahari. Menjalankan ibadah puasa adalah kegiatan menahan makan dan minum, serta hubungan seksual dan segala sesuatu yang dapat membatalkan puasa. Salah satu hikmah ibadah puasa pada bulan Ramadhan yang berkenaan dengan pola konsumsi pada bulan Ramadhan adalah terciptanya perilaku yang disiplin dalam mengelola hawa nafsu, sehingga tidak berlebih-lebihan dalam konsumsi. Namun berdasarkan fenomena yang berkembang ternyata justru pada bulan Ramadhan terjadi peningkatan pengeluaran konsumsi. Hal tersebut berdasarkan data wawancara dengan beberapa anggota masyarakat kota Jambi yang memberikan pernyataan bahwa pada bulan Ramadhan mereka mengalami peningkatan konsumsi.

Berdasarkan data di atas peningkatan pengeluaran konsumsi setiap responden bervariasi, namun nilai frekuensi yang tertinggi terdapat pada interval $40 \%$ sampai dengan $70 \%$. Hal ini membuktikan bahwa kenaikan pengeluaran konsumsi menunjukan sesuatu yang sangat bertentangan dengan anjuran dari hikmah berpuasa yaitu mengontrol diri dengan tidak berlebih-lebihan dalam konsumsi. Peningkatan konsumsi bulan Ramadhan pada masyarakat kota Jambi salah satunya juga dipengaruh faktor sosial dimana referensi keluarga, teman, status sosial dan kebudayaan turut memberikan sumbangsih dalam peningkatan konsumsi pada bulan Ramadhan.

\section{Pengertian Perilaku Konsumen}

Para ahli berpendapat mengenai defenisi perilaku konsumen, menurut Schiffman dan Kanuk perilaku konsumen studi unit-unit dan proses pembuatan keputusan yang terlibat dalam penerimaan, penggunaan dan pembelian, dan penentuan barang, jasa dan ide. (Sangaji, Sopian,2013) Sementara itu menurut Hawkins, Best, dan Coney Perilaku konsumen adalah studi mengenai individu, kelompok atau organisasi dan proses dimana mereka menyeleksi, menggunakan dan membuang produk, layanan, pengalaman atau ide untuk memuaskan kebutuhan dan dampak dari proses tersebut pada konsumen dan masyarakat. (Rinidwiastuti,2008:18) Menurut Engel perilaku konsumsi adalah tindakan yang terlibat langsung dalam mendapatkan, mengonsumsi dan menghabiskan produk dan jasa, termasuk proses keputusan yang mendahului dan mengikuti tindakan itu. Dan menurut Loudon dan Bitta, perilaku konsumsi adalah suatu proses pengambilan keputusan yang mensyaratkan perilaku individu untuk mengevaluasi, memperoleh, menggunakan dan mengatur barang dan jasa. Adapun menurut Kotler dan Amstrong, perilaku konsumsi adalah perilaku individu ataupun rumah tangga dalam bentuk pembelian barang dan jasa untuk konsumsi personal. ( Andi Bahri, 2014 ).

Menurut Asosiasi Marketing Amerika mendefinisikan perilaku konsumsi ialah interaksi yang bersifat dinamis disertai afeksi, kognisi, tindakan dan lingkungan dalam melakukan kegiatan pertukaran. (Kholiq Mohtarom, 2010) Sementara itu menurut definisi lain perilaku konsumen dapat diartikan sebagai studi tentang unit pembelian dan proses pertukaran yang melibatkan perolehan, konsumsi, dan pembuangan barang, jasa, pengalaman serta ide-ide. (Irham Fahmi, 2016). Dari beberapa pendapat dari para ahli di atas dapat disimpulkan bahwa perilaku konsumen adalah sifat atau perilaku individu atau kelompok yang berkaitan dengan pemenuhan kebutuhan dengan cara membeli, menggunakan jasa dalam rangka pemenuhan tingkat kepuasan.

\section{Pengaruh Kelompok Referensi Terhadap Pola Konsumsi}

Dalam sebuah penelitian juga menunjukan bahwa kelompok referensi mempunyai pengaruh. Pengaruh teman sebaya dan pemahaman interpretasi tentang etika tentang produk apa yang akan dibeli memberikan motivasi utama untuk keputusan konsumsi.(Davies, 2016) Dalam sebuah makalah penelitian membahas tentang pengaruh kelompok referensi melalui gagasan orang banyak tentang beberapa pakaian yang digunakan untuk berbagai situasi sosial. Penelitian menggunakan wawancara tentang alasan mereka memilih sebuah pakaian dan mereka gunakan untuk apa. Hasil temuan menyimpulkan bahwa narasi latihan peran konsumen memunculkan proses yang dilalui oleh masing-masing individu untuk mengantisipasi interaksi sosial. Hal tersebut tergantung pada situasi sosial, teori yang melatarbelakangi, harapan, lokasi, pembelajaran dan keterampilan. Audiens yang dibayangkan dari berbagai kelompok referensi memang memengaruhi perilaku individu di masa depan. (Schulz, 2015) Sebuah penelitian juga mengungkapkan teori 
yang sama yang menyatakan bahwa kelompok referensi mempengaruhi faktor sosial. Penelitian ini membahas masalah menguji pengaruh teman dalam konteks pembelian produk yang dikonsumsi bersama. Fokus penelitian ini adalah pada strategis yang digunakan mahasiswa untuk metode persuasi dan perlawanan ketika menghadiri sebuah acara atau sebuah festival. Hasil temuan menunjukan bahwa masing-masing individu memberikan argumen dengan teknik penyampaian tertentu. Beberapa strategi ini hanya berlaku untuk kelompok referensi yang memiliki sejarah mengkonsumsi produk bersama, karena mereka menggunakan pengalaman masa lalu sebagai sarana untuk menghasilkan argumen persuasi atau perlawanan. Sejauh mana pengaruhnya dibahas sebagai sangat subyektif dan tergantung pada konteks tertentu dari latihan persuasi.

\section{Pengaruh Kelas Sosial Terhadap Pola Konsumsi}

Dalam sebuah penelitian mengenai prefensi makanan di sekolah Jerman dan di Inggris dan dianalisis berdasarkan pengaruh dari kebudayaan, jenis kelamin dan kelas sosial. Ada perbedaan yang signifikan dalam proporsi anak-anak yang membawa cokelat ke sekolah diberbagai kelas sosial di Inggris dan Jerman terdapat perbedaan yang signifikan dalam jumlah total cokelat yang dikonsumsi setiap minggu oleh kelas sosial yang berbeda di kedua negara. Pilihan makanan ringan yang populer di kedua negara menunjukan perbedaan yang sangat signifikan antara anak-anak Jerman dan Inggris, anak-anak Jerman lebih memilih makanan sehat seperti buah-buahan, yogurt dan cemilan kue bolu. Sedangkan anak-anak di Inggris memilih produk cokelat dari lima item yang paling disukai. Alasan untuk perbedaan tersebut dapat dikaitkan dengan pengaruh iklan, pengalaman pendidikan gizi, sikap orang tua, kenyamanan dan ketersediaan, kendala pendapatan dan faktor psikologis.( Körtzinger, I., Neale, R. J., \& Tilston, 1994). Penelitian selanjutnya juga mengemukan hal yang sama bahwa kelas sosial mempunyai pengaruh terhadap faktor sosial. Hasil temuan menunjukan kelas sosial dianggap penentu penting dalam perilaku konsumen. Sebagian besar penelitian sebelumnya telah berfokus pada perilaku pembelian dan konsumsi di seluruh segmen kelas sosial di tingkat kelas produk generik. Sebaliknya, artikel ini melaporkan studi eksplorasi tentang bagaimana merek dari kelompok produk dan layanan yang dipersepsikan secara sempit dianggap menarik bagi kelas sosial yang berbeda.( Grønhaug, K., \& Trapp, P. S,1988)

\section{Pengaruh Budaya Terhadap Pola Konsumsi}

Dalam artikel ini bertujuan membahas hubungan budaya dan perilaku wisatawan. Fokus dari penelitian ini melihat budaya individualisme dan kolektivisme serta tujuan perjalanan kelompok. Artikel ini berusaha untuk menyatakan bahwa niat dan perilaku perjalanan kelompok tidak hanya dipengaruhi oleh latar belakang budaya individualisme atau kolektivisme, tetapi juga fungsi dari beberapa faktor termasuk pengaruh sosial, politik, dan ekonomi, serta latar belakang pribadi pelancong individu. (Meng, 2010) Hasil penelitian yang lain dilakukan terhadap orang Lahu Thailand yang telah memulai mengkonsumsi alkohol rata-rata usia 12 tahun. Kebudayaan mereka menganggap bahwa mengkonsumsi alkohol digunakan sebagai suatu tanda kedewasaan dan juga digunakan sebagai cara untuk mendapatkan penerimaan sosial dari orang lain di masyarakat. Alkohol dikonsumsi oleh orang muda, tua laki-laki dan wanita. Faktor yang menyebabkan mereka mengkonsumsi alkohol karena pengaruh tingkat pendapatan, perilaku orang tua, pengaruh teman sebaya, rasa dan adaptasi budaya.( Detpitukyon, S., Apidechkul, T., Sunsern, R., Anuwatnonthakate, A., Singhhorn, O., Putsa, B., \& Thutsanti, 2018). Hal yang sama juga menyatakan tentang pengaruh budaya dalam kehidupan sosial. Dimana hasil penelitian di Malaysia menunjukan bahwa lima faktor kerangka budaya energi yang berkontribusi pada perilaku konsumsi energi yaitu, peraturan bangunan, kepedulian dan faktor langsung (perangkat dan kegiatan). Faktor ini memprediksi tingkat konsumsi 78 persen dengan menggunakan responden sebesar 1.009.(Ishak, 2017) Hasil temuan lain sebuah penelitian yang dilakukan di Afrika mengenai perilaku budaya dalam pengaruh sosial ekonomi konsumen. Data ini dikumpulkan dari Negeria, Kenya dan Afrika Selatan melalui survei, diskusi dan wawancara. Temuan mengungkapkan bahwa pembeli Afrika membeli sebagian besar bahan habis pakai untuk konsumsi rumah tangga. Tawar-menawar harga juga merupakan suatu hal yang biasa di antara pembeli Afrika. Temuan lebih lanjut menunjukkan bahwa sifat rumah tangga, budaya lokal dan penggunaan teknologi adalah beberapa faktor yang mempengaruhi perilaku konsumen Afrika. Data juga menunjukkan bahwa pengumpulan informasi dan pengaruh orang lain sangat penting dalam keputusan konsumen di Afrika.( Uzo, 
U., Zephania Opati, T., \& Shittu, O,2018)

\section{METODE PENELITIAN}

Penelitian ini mengunakan pendekatan analisis penelitian kualitatif deskriptif dengan menggunakan metode kuesioner. Populasi dalam penelitian ini adalah seluruh masyarakat Kota Jambi yang melaksanakan ibadah puasa pada bulan Ramadhan dengan penentuan sampel menggunakan teknik random sampling berjumlah 140 responden. Penentuan sampel bersifat insidental artinya penentuan sampel berdasarkan pengumpulan data melalui responden yang ditemui secara langsung dilapangan.

\section{HASIL DAN PEMBAHASAN \\ Indikator Variabel Kelompok Referensi}

Berdasarkan hasil data mentah untuk variabel kelompok referensi (X16) yang bersumber dari penyebaran angket dari 140 responden dengan jumlah pernyataan 6 butir instrumen dan variasi jawaban dengan menggunakan skala liskert 1 s.d 5 maka dapat diketahui persentase skor dari masing-masing skor :

Tabel 1

Deskripsi Data Variabel Kelompok Referensi

\begin{tabular}{|c|c|c|c|c|c|c|c|c|}
\hline \multirow{2}{*}{ No } & \multirow{2}{*}{ Instrumen } & \multicolumn{5}{|c|}{ Kategori } & \multirow{2}{*}{$\begin{array}{l}\text { Rata- } \\
\text { rata }\end{array}$} & \multirow{2}{*}{ Kriteria } \\
\hline & & 1 & 2 & 3 & 4 & 5 & & \\
\hline \multirow[t]{2}{*}{1} & \multirow{2}{*}{$\begin{array}{l}\text { Membeli produk makanan } \\
\text { informasi tetangga }\end{array}$} & 4 & 27 & 29 & 70 & 9 & 3,39 & \multirow{2}{*}{ Setuju } \\
\hline & & 2,9 & 19 & 20,7 & 50 & 6,43 & 67,7 & \\
\hline \multirow[t]{2}{*}{2} & \multirow{2}{*}{$\begin{array}{l}\text { Membeli pakaian referensi Istri } \\
\text { dan keluarga }\end{array}$} & 3 & 28 & 21 & 72 & 14 & 3,46 & \multirow{2}{*}{ Setuju } \\
\hline & & 2,1 & 20 & 15 & 51,4 & 10 & 69,3 & \\
\hline \multirow[t]{2}{*}{3} & \multirow{2}{*}{$\begin{array}{l}\text { Informasi teman tentang produk } \\
\text { makanan }\end{array}$} & 1 & 16 & 12 & 88 & 23 & 3,83 & \multirow{2}{*}{ Setuju } \\
\hline & & 0,7 & 11 & 8,57 & 62,9 & 16,4 & 76,6 & \\
\hline \multirow[t]{2}{*}{4} & \multirow{2}{*}{$\begin{array}{l}\text { Mengetahui Etika konsumsi dari } \\
\text { referensi buku keislaman }\end{array}$} & $\mathrm{O}$ & 8 & 24 & 71 & 36 & 3,97 & \multirow{2}{*}{ Setuju } \\
\hline & & $\mathrm{O}$ & 5,7 & 17,1 & 50,7 & 25,7 & 79,4 & \\
\hline \multirow[t]{2}{*}{5} & \multirow{2}{*}{$\begin{array}{l}\text { Informasi dari media iklan } \\
\text { tentang produk makanan }\end{array}$} & 15 & 36 & 21 & 52 & 15 & 3,12 & \multirow{2}{*}{ Setuju } \\
\hline & & 11 & 26 & 15 & 37,1 & 10,7 & 62,4 & \\
\hline \multirow[t]{2}{*}{6} & \multirow{2}{*}{$\begin{array}{l}\text { Mendapat referensi dari media } \\
\text { sosial seperti whatssap d11. }\end{array}$} & 12 & 31 & 22 & 57 & 18 & 3,27 & \multirow{2}{*}{ Setuju } \\
\hline & & 8,6 & 22 & 15,7 & 40,7 & 12,9 & 65,4 & \\
\hline \multicolumn{7}{|c|}{ Rata-rata } & 70,1 & Setuju \\
\hline
\end{tabular}

Sumber : diolah dari data angket

Hasil pengumpulan data tersebut diketahui bahwa rata-rata perolehan skor pada hasil sebaran kuesioner ialah $70,1 \%$ dimana perolehan nilai skor tertinggi $(79,4 \%)$ terdapat pada indikator Mengetahui etika konsumsi dari referensi buku keislaman dan perolehan nilai skor terendah $(62,4 \%)$ terdapat pada indikator " informasi dari media iklan tentang produk makanan. Berdasarkan data tersebut dapat diinterpretasikan bahwa masyarakat kota Jambi mempunyai referensi dalam kegiatan konsumsi yaitu bersumber dari buku keislaman, teman, keluarga, media sosial dan informasi melalui iklan. Nilai 70,1\% menunjukan pernyataan setuju bahwa ada beberapa kelompok referensi yang memberikan rekomendasi kepada masyarakat kota Jambi pada bulan Ramadhan mengenai sejumlah produk konsumsi. Lebih lanjut sebaran data dari kuesioner dapat dilihat dari lampiran disertasi.

\section{Indikator Variabel Kelas Sosial}

Berdasarkan hasil data mentah variabel kelas sosial (X17) yang disebarkan melalui kuesioner dengan jumlah responden 140 dan jumlah pertanyaan 4 butir instrumen dengan variasi jawaban skala likert 1 s.d. 5 maka diketahui perolehan masing-masing persentase indikator. Tabel 2 memberikan gambaran bahwa indikator kelas sosial diketahui memperoleh nilai rata-rata persentase $61,2 \%$ dimana perolehan nilai skor tertinggi $(67,7 \%)$ terdapat pada indikator " Pola konsumsi berdasarkan status profesi" dan perolehan nilai skor paling rendah $(54,7 \%)$ terdapat pada indikator "Mempersiapkan konsumsi lebaran berdasarkan status sosial. Hasil perolehan nilai skor tersebut dapat diinterpretasikan bahwa persiapan konsumsi masyarakat kota Jambi pada bulan Ramadhan dan penyambutan hari lebaran disesuaikan dengan status profesi dan sosial. Nilai $61,2 \%$ berada dalam rentang $61 \%-70 \%$ dengan skala penilaian setuju. Artinya kelas sosial merupakan salah satu pertimbangan masyarakat kota Jambi dalam menentukan pola konsumsi yang akan 
dilakukan. Hasil data sebaran kuesioner dapat dilihat pada lampiran disertasi.

Tabel 2

Deskripsi Data Variabel Kelas Sosial

\begin{tabular}{|c|c|c|c|c|c|c|c|c|}
\hline \multirow{2}{*}{ No } & \multirow{2}{*}{ Instrumen } & \multicolumn{5}{|c|}{ Kategori } & \multirow{2}{*}{$\begin{array}{l}\text { Rata- } \\
\text { rata }\end{array}$} & \multirow{2}{*}{ Kriteria } \\
\hline & & 1 & 2 & 3 & 4 & 5 & & \\
\hline \multirow[t]{2}{*}{1} & \multirow{2}{*}{$\begin{array}{l}\text { Memunuhi kebutuhan berdas arkan } \\
\text { tingkat kekaya an }\end{array}$} & 14 & 35 & 30 & 43 & 18 & 3,11 & \multirow{2}{*}{ Setuju } \\
\hline & & 10 & 25 & 21,4 & 30,7 & 12,9 & 62,3 & \\
\hline \multirow[t]{2}{*}{2} & \multirow{2}{*}{$\begin{array}{l}\text { Pol a konsumsi berdasarkan status } \\
\text { profesi }\end{array}$} & 13 & 27 & 17 & 59 & 24 & 3,39 & \multirow{2}{*}{ Setuju } \\
\hline & & 9,29 & 19,3 & 12,1 & 42,1 & 17,1 & 67,7 & \\
\hline \multirow[t]{2}{*}{3} & \multirow{2}{*}{$\begin{array}{l}\text { Meras a malu meli hat keluarga tidak } \\
\text { memakai baju baru waktu lebaran }\end{array}$} & 23 & 38 & 15 & 44 & 20 & 3 & \multirow{2}{*}{ Setuju } \\
\hline & & 16,4 & 27,1 & 10,7 & 31,4 & 14,3 & 60 & \\
\hline \multirow[t]{2}{*}{4} & \multirow{2}{*}{$\begin{array}{l}\text { Mempersiapkan konsumsi lebaran } \\
\text { berdasarkan status sosial }\end{array}$} & 19 & 48 & 28 & 41 & 4 & 2,74 & \multirow{2}{*}{ Netral } \\
\hline & & 13,6 & 34,3 & 20 & 29,3 & 2,86 & 54,7 & \\
\hline \multicolumn{7}{|c|}{ Rata-rata } & 61,2 & Setuju \\
\hline
\end{tabular}

Sumber : diolah dari data angket

\section{Indikator Variabel Budaya/ Sub budaya}

Berdasarkan hasil data mentah variabel budaya/ sub budaya (X18) yang disebarkan melalui kuesioner dengan jumlah responden 140 dan jumlah pertanyaan 6 butir instrumen dengan variasi jawaban skala likert 1 s.d. 5 maka diketahui perolehan masing-masing persentase indikator :

Tabel 3

Deskripsi Data Variabel Budaya

\begin{tabular}{|c|c|c|c|c|c|c|c|c|}
\hline \multirow{2}{*}{ No } & \multirow{2}{*}{ Instrumen } & \multicolumn{5}{|c|}{ Kategori } & \multirow{2}{*}{$\begin{array}{l}\text { Rata- } \\
\text { rata }\end{array}$} & \multirow{2}{*}{ Kriteria } \\
\hline & & 1 & 2 & 3 & 4 & 5 & & \\
\hline \multirow[t]{2}{*}{1} & \multirow{2}{*}{$\begin{array}{l}\text { Membuat makanan ta jil menjadi } \\
\text { tradisi berbuka }\end{array}$} & 2 & 11 & 10 & 74 & 43 & 4,04 & \multirow{2}{*}{ Sangat Setuju } \\
\hline & & 1,429 & 7,86 & 7,14 & 52,9 & 30,7 & 80,7 & \\
\hline \multirow[t]{2}{*}{2} & \multirow{2}{*}{$\begin{array}{l}\text { Memakai baju baru lebaran } \\
\text { meniadi tradisi keluarga }\end{array}$} & 2 & 15 & 15 & 73 & 35 & 3,89 & \multirow{2}{*}{ Setuju } \\
\hline & & 1,429 & 10,7 & 10,7 & 52,1 & 25 & 77,7 & \\
\hline \multirow[t]{2}{*}{3} & \multirow{2}{*}{$\begin{array}{l}\text { Berbuka bersama menj adi tradi si } \\
\text { puasa Ramadhan }\end{array}$} & 0 & 4 & 9 & 100 & 27 & 4,07 & \multirow{2}{*}{ Sangat Setuju } \\
\hline & & 0 & 2,86 & 6,43 & 71,4 & 19,3 & 81,4 & \\
\hline \multirow[t]{2}{*}{4} & \multirow{2}{*}{$\begin{array}{l}\text { Memberikan bingkisan } 1 \text { ebaran } \\
\text { dan THR jadi Tradisi }\end{array}$} & 5 & 15 & 16 & 95 & 13 & 3,74 & \multirow{2}{*}{ Setuju } \\
\hline & & 3,571 & 10,7 & 11,4 & 67,9 & 9,29 & 74,9 & \\
\hline \multirow[t]{2}{*}{5} & \multirow{2}{*}{$\begin{array}{l}\text { Membuat kue untuk lebaran } \\
\text { meniadi budaya umat Islam }\end{array}$} & 1 & 8 & 7 & 76 & 48 & 4,16 & \multirow{2}{*}{ Sangat Setuju } \\
\hline & & 0,714 & 5,71 & 5 & 54,3 & 34,3 & 83,1 & \\
\hline \multirow[t]{2}{*}{6} & \multirow{2}{*}{$\begin{array}{l}\text { Mudik sebagai tradisi umat untuk } \\
\text { silaturrahmi kel uarga }\end{array}$} & 3 & 15 & 19 & 82 & 21 & 3,74 & \multirow{2}{*}{ Setuju } \\
\hline & & 2,143 & 10,7 & 13,6 & 58,6 & 15 & 74,7 & \\
\hline \multicolumn{7}{|c|}{ Rata-rata } & 78,8 & Setuju \\
\hline
\end{tabular}

Sumber : diolah dari data angket

Hasil pengumpulan data tersebut diketahui bahwa rata-rata perolehan skor pada hasil sebaran kuesioner ialah $78,8 \%$ dimana perolehan skor yang paling tertinggi $(83,1 \%)$ terdapat pada indikator " Membuat kue menjadi budaya umat Islam" dan perolehan skor nilai yang paling terendah $(74,9 \%)$ terdapat pada indikator "Memberikan bingkisan dan tunjangan hari lebaran (THR) menjadi tradisi". Berdasarkan data tersebut dapat diinterpretasikan bahwa membuat kue, memberikan bingkisan dan tunjangan hari raya (THR) sudah menjadi tradisi dan menjadi sebuah kebudayaan ketika memasuki bulan Ramadhan dan hari lebaran. Tradisi tersebut telah dilakukan sejak lama hingga sampai sekarang dan bentuk bingkisan yang diberikan tentu disesuaikan dengan perkembangan zaman. Hasil nilai skor rata-rata keseluruhan $78,8 \%$ berada pada rentang interval penilaian $71 \%-80 \%$ dalam penilaian kategori setuju. Artinya beberapa kegiatan konsumsi yang dilakukan pada saat bulan Ramadhan seperti membuat makanan 
ta jil, berbuka bersama dan kegiatan konsumsi dalam rangka menyambut hari lebaran seperti membeli baju baru, membuat kue lebaran dan mudik adalah bentuk tradisi yang sudah membudaya dalam masyarakat kota Jambi. Tradisi yang berkembang berdasarkan pemahaman religiusitas mereka dan rasa syukur atas segala nikmat yang telah diberikan. Tahap selanjutnya data sebaran kuesioner dapat dilihat pada lampiran disertasi.

\section{SIMPULAN}

Berdasarkan pembahasan di atas dapat disimpulkan bahwa pola konsumsi masyarakat kota Jambi dilihat dari faktor sosial dipengaruhi oleh kelompok referensi dimana setiap masyarakat kota Jambi mendapatkan referensi dari buku keislaman, keluarga, teman dan berasal dari media cetak dan elektronik. Sementara itu indikator kelas sosial menjadi sebuah pengaruh dalam pola konsumsi pada masyarakat Kota Jambi pada bulan Ramadhan dilihat dari persiapan konsumsi lebaran dilakukan berdasarkan tingkat status sosialnya di tengah masyarakat. Indikator budaya berpengaruh terhadap pola konsumsi masyarakat kota Jambi dilihat dari tradisi mereka membuat dan membeli bermacam makanan dan minuman untuk ta jil berbuka puasa, membuat bermacam kue untuk lebaran, membeli baju baru, Mudik dan memberikan hadiah dalam bentuk THR.

\section{DAFTAR PUSTAKA}

Andi Bahri, Etika Konsumsi Menurut Perpektif Ekonomi Islam, Jurnal Studia Islamika Vol. 11, 2014

Detpitukyon, S., Apidechkul, T., Sunsern, R., Anuwatnonthakate, A., Singhhorn, O., Putsa, B., \& Thutsanti, P. Patterns and perception of alcohol drinking among the Lahu people, Northern Thailand, Journal of Health Research, Vol. 32, 2018

Davies, I. A., \& Gutsche, S. Consumer motivations for mainstream "ethical" consumption, European Journal of Marketing, Vol. 50, 2016

Grønhaug, K., \& Trapp, P. S. Perceived Social Class Appeals Of Branded Goods and Services. 1988, Journal of Services Marketing, Vol.2,1988

Irham Fahmi, Perilaku Konsumen Teori dan Aplikasi. Bandung : Alfabeta, 2016

Ishak, M. H. Modelling energy consumption behaviour using "energy culture" concept for student accommodations in Malaysian public universities, Facilities, Vol. 35, 2017

Körtzinger, I., Neale, R. J., \& Tilston, C. H. Children's Snack Food Consumption Patterns in Germany and England, British Food Journal, Vol.96, 1994

Kholiq Muhtarom, Perilaku Konsumsi Masyarakat Jakarta Timur Sebelum dan Sesaat Ramadhan, Al-Iqtishad,Vol. 2, 2010

Meng, F. Individualism/collectivism and group travel behavior: a cross-cultural perspective, International Journal of Culture, Tourism and Hospitality Research, Vol. 4, 2010

Rinidwiastuti dkk, Ilmu Perilaku Konsumen. Malang: Universitas Brawijaya Press, 2008

Schulz, H. M. Reference group influence in consumer role rehearsal narratives, Qualitative Market Research: An International Journal, Vol.18, 2015

Sangaji, Sopiah, Perilaku Konsumen Pendekatan Praktis. Yogyakarta: C.V. Andi, 2013

Uzo, U., Zephania Opati, T., \& Shittu, O. Characteristics of the African Buyer's Purchase Behaviour, Indigenous 